\title{
Detection and characterization of extreme wind speed ramps
}

\author{
Ásta Hannesdóttir and Mark Kelly \\ DTU Wind Energy Dept., Technical University of Denmark, Roskilde, Denmark \\ Correspondence: Ásta Hannesdóttir (astah@dtu.dk)
}

Received: 17 October 2018 - Discussion started: 16 January 2019

Revised: 9 April 2019 - Accepted: 17 May 2019 - Published: 9 July 2019

\begin{abstract}
The present study introduces a new method to characterize ramp-like wind speed fluctuations, including coherent gusts. This method combines two well-known methods: the continuous wavelet transform and the fitting of an analytical form based on the error function. The method provides estimation of ramp amplitude and rise time, and is herein used to statistically characterize ramp-like fluctuations at three different measurement sites. Together with the corresponding amplitude of wind direction change, the ramp amplitude and rise time variables are compared to the extreme coherent gust with direction change from the IEC wind turbine safety standard. From the comparison we find that the observed amplitudes of the estimated fluctuations do not exceed the one prescribed in the standard, but the rise time is generally much longer, on average around $200 \mathrm{~s}$. The direction change does however exceed the one prescribed in the standard several times, but for those events the rise time is a minute or more. We also demonstrate a general pattern in the statistical behaviour of the characteristic ramp variables, noting their wind speed dependence, or lack thereof, at the different sites.
\end{abstract}

\section{Introduction}

The IEC wind turbine safety standard prescribes various models of extreme wind conditions that a wind turbine must withstand during its operational lifetime (IEC, 2005). One of those prescribed models is an extreme coherent gust with direction change (ECD), used for ultimate load prediction. The ECD model is presented in Stork et al. (1998), but with a rather limited description; the model is not shown compared to measurements, but it is said to represent extreme gusts and direction changes in wind speed measurements "quite well." However, the ECD prescription was found later by Hansen and Larsen (2007) to give reasonable estimates compared with measurements.

With the increasing rotor size of modern wind turbines, resent research has focused on how the gust models in the IEC standard are unrealistically represented by a uniform wave (Bierbooms, 2005; Bos et al., 2014). In these studies, gusts are defined as extreme fluctuations of stationary and homogeneous turbulence. The gusts are simulated with stochastic simulations and constrained in space to have a finite length scale. Using such gust models for wind turbine load simulations generally results in lower loads than when using the uniform gust models of the IEC standard. The reason is due to the limited length scale of the gusts, and that during the simulations some gusts might even miss the blades as they sweep by the rotor. The authors of these studies suggest that the uniform gust models of the IEC standard should consequently be replaced by stochastic gust models.

There are however many studies in the field of atmospheric science that investigate large coherent structures in turbulent flow (e.g. Mahrt, 1991; Barthlott et al., 2007; Fesquet et al., 2009; Belušić and Mahrt, 2012). These studies take into consideration fluctuations of larger scales than those of stationary, homogeneous turbulence, i.e. the submesoscale or mesoscale. These coherent structures are seen in measurements as ramp-like increases in wind speed that may readily be compared with the ECD due to similar characteristics. The coherent structures can be driven by a broad range of different meteorological processes. In the stable boundary layer they may be generated by e.g. gravity waves, KelvinHelmholtz instabilities, surface heterogeneity, or pressure 


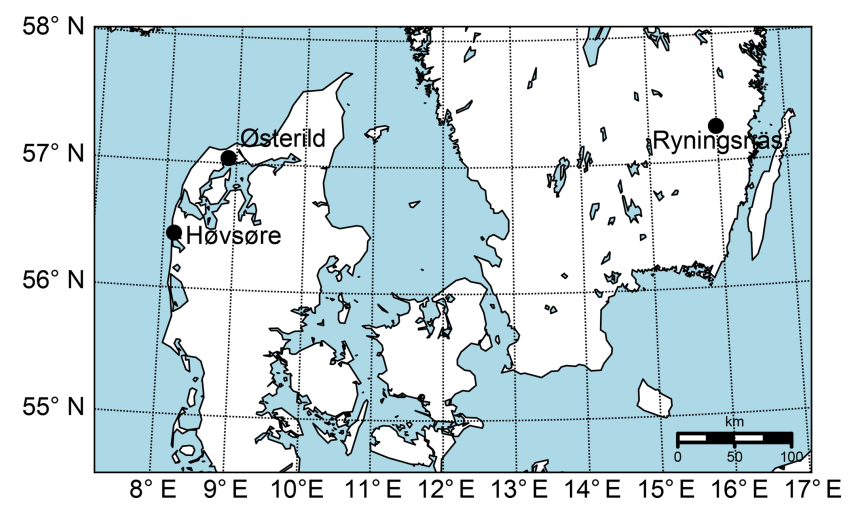

Figure 1. A map of Denmark and southern Sweden showing the locations of the measurement sites.

disturbances (Mahrt, 2010). In the convective boundary layer they may be generated by e.g. surface buoyancy fluxes, latent heat release, or cloud radiative effects, and may be observed in the form of convective cells and rolls (Drobinski et al., 1998; Young et al., 2002). In the neutral boundary layer they may be generated by shear and can be observed in the form of streaks (Foster et al., 2006). Some processes are bound to certain terrain; e.g. coherent structures may be generated by dynamics between the flow and plant canopy (Finnigan, 2000), or in coastal and offshore regions they may be driven by open cellular convection (e.g. Vincent et al., 2012).

In this study we focus on large-scale, high-amplitude (extreme) fluctuations, which are coherent across the rotor of any multi-megawatt wind turbine. We examine data from three sites with different terrain types and characterize the fluctuations. In order to characterize the amplitude and rise time of the investigated fluctuations, we provide a new combination of two well-known methods: the continuous wavelet transform and the fitting of an idealized ramp function (based on the error function), which is inspired by detection of atmospheric boundary-layer depth (Steyn et al., 1999). The method provides a single characteristic rise time and a corresponding amplitude of measured extreme wind speed fluctuations. The focus in the present study is not related to ramp forecasting or wind power ramps (Sevlian and Rajagopal, 2013), but rather characterization of extreme wind speed ramps that may be considered for load purposes. We investigate whether the characteristics of the extreme wind speed ramps are comparable with the ECD.

\section{Sites and measurements}

The measurements used for the characterization of the ramplike events come from three different sites. The locations of the measurement sites may be seen in Fig. 1.

\subsection{Høvsøre}

The Høvsøre National Test Centre for Wind Turbines is located on the western coast of Jutland, approximately $1.7 \mathrm{~km}$ east of the coastline. The site is in a coastal agricultural area where the terrain is nearly flat.

Several masts with measurement instruments are located at the site, which has been in operation since 2004. In the current analysis we use measurements from a light mast with cup anemometers and wind vanes installed at 60, 100, and $160 \mathrm{~m}$ heights. The light mast is located between two of the test wind turbines which are separated by approximately $300 \mathrm{~m}$ in the north-south direction. The dominating wind direction is from north-west, the annual average $10 \mathrm{~min}$ wind speed at the light mast is $V_{\text {ave }}=9.33 \mathrm{~m} \mathrm{~s}^{-1}$ at $100 \mathrm{~m}$, and the reference turbulence intensity is $I_{\text {ref }}=0.065^{1}$. The data used in this study consist of $10 \mathrm{~Hz}$ measurements from September 2004 to December 2014. A detailed overview of the site and instrumentation may be found in Peña et al. (2016).

\section{2 Østerild}

The Østerild National Test Centre for Large Wind Turbines is located in a forested area in northern Jutland. The distance to the coast is approximately $4 \mathrm{~km}$ to the north and $20 \mathrm{~km}$ to the west. The site has two $250 \mathrm{~m}$ tall light masts equipped with sonic anemometers at $37,103,175$, and $241 \mathrm{~m}$. In this analysis we use measurements from the southern mast, where the terrain around the mast is flat and the surrounding forest has a canopy height between 10 and $20 \mathrm{~m}$. To the west of the mast there is a narrow clearing of the forest with a grass field. The clearing is approximately $1 \mathrm{~km}$ long in the eastwest direction and $200 \mathrm{~m}$ wide in the north-south direction. The mast is located approximately $300 \mathrm{~m}$ south-west of a row of seven wind turbines aligned in the north-south direction. At the southern light mast, the annual average $10 \mathrm{~min}$ wind speed is $V_{\text {ave }}=7.94 \mathrm{~m} \mathrm{~s}^{-1}$ at $103 \mathrm{~m}$ height and the reference turbulence intensity is $I_{\text {ref }}=0.13$. The data used in this study consist of $20 \mathrm{~Hz}$ measurements from March 2015 to February 2018 at 37, 103, and $175 \mathrm{~m}$ heights. More details on the site may be found in Hansen et al. (2014).

\subsection{Ryningsnäs}

The Ryningsnäs measurement site is located approximately $30 \mathrm{~km}$ inland from the south-eastern coast of Sweden. The terrain is forested and generally flat. The forest has a $200 \mathrm{~km}$ fetch in the westerly direction and the tree height around the site is between 20 and $25 \mathrm{~m}$. There is a $138 \mathrm{~m}$ tall meteorological mast equipped with sonic anemometers at 40, 59, 80, 98,120 , and $138 \mathrm{~m}$ measuring at $20 \mathrm{~Hz}$ sampling frequency. In this analysis we use the measurements at 59, 98, and $138 \mathrm{~m}$

\footnotetext{
${ }^{1} I_{\text {ref }}:$ the average 10 min turbulence intensity evaluated at a wind speed of $15 \mathrm{~m} \mathrm{~s}^{-1}$.
} 
heights from a period between November 2010 and December 2011. There are two wind turbines approximately $200 \mathrm{~m}$ from the mast, one in the southerly direction and the other in the north-easterly direction. The annual average $10 \mathrm{~min}$ wind speed is $V_{\text {ave }}=5.94 \mathrm{~m} \mathrm{~s}^{-1}$ at $98 \mathrm{~m}$ height and the reference turbulence intensity is $I_{\text {ref }}=0.18$. More details on the site and measurements may be found in Arnqvist et al. (2015).

\section{Selection and characterization of events}

In this section we go through the steps of selecting and characterizing the ramp-like coherent structures. There are three steps in the procedure.

1. Identify events of extreme variance, indicating largescale fluctuations, and acquire $30 \mathrm{~min}$ wind speed measurements for each event.

2. Estimate the timescale and position in time (timing) of the dominating fluctuation using wavelet transform.

3. Characterize the amplitude and rise time of the dominating fluctuation by fitting an idealized ramp function to a subset of the wind speed signal, whose timing and scale are found by the wavelet transform.

\subsection{First step: selecting high-variance events}

Here we select the ramp events by comparing two different data sets: one where the $10 \mathrm{~min}$ standard deviation is calculated from the raw measurements $\left(\sigma_{\text {raw }}\right)$ and the other where the measurements have been high-pass filtered (with fluctuation amplitude $\sigma_{\text {filt }}$ ). The 10 min standard deviations are calculated using predefined windows (00:00-00:10, 00:1000:20, etc.). A significant reduction in the $10 \mathrm{~min}$ standard deviation by high-pass filtering occurs when the measurement window includes a ramp-like fluctuation, as the latter causes a high observed standard deviation $\sigma_{\text {raw }}$ (Hannesdóttir et al., 2019).

The filtering is performed with a second-order Butterworth filter where the cut-off frequency is chosen as

$f_{c}=\frac{U}{L}$,

where $U$ is the 10 min mean wind speed and $L$ is a length scale, here chosen to be $2000 \mathrm{~m}$. This choice of cut-off frequency removes trends and fluctuations involved with length scales larger than $2000 \mathrm{~m}$.

In order to identify where the 10 min standard deviation is reduced the most by filtering, we calculate the ratios of $\sigma_{\text {raw }} /\left(\sigma_{\text {filt }}+1\right)$ and identify the highest $0.1 \%$ from each data $\mathrm{set}^{2}$. We then acquire $30 \mathrm{~min}$ samples of high-frequency measurements for each event for further analysis and characterization. By using $30 \mathrm{~min}$ samples we ensure that we have

\footnotetext{
${ }^{2}$ Here $\sigma_{\text {filt }}$ is shifted by 1 to put emphasis on high $\sigma$ values. Otherwise only ratios where $\sigma_{\text {filt }} \ll 1$ are selected.
}

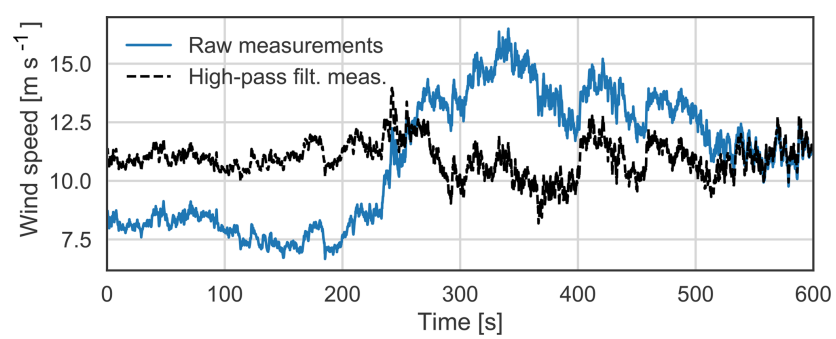

Figure 2. Wind speed measurements from $100 \mathrm{~m}$ at Høvsøre, raw measurements (blue line), and high-pass filtered measurements (dashed black line).

enough measurements before and/or after the ramp-like wind speed increase.

An example of an extreme-variance event may be seen in Fig. 2, where $10 \mathrm{~min}$ "raw" wind speed measurements are compared with filtered measurements.

This example is taken from the light mast in Høvsøre at $100 \mathrm{~m}$. The $10 \mathrm{~min}$ standard deviation of the raw measurements is $2.66 \mathrm{~m} \mathrm{~s}^{-1}$ but $0.75 \mathrm{~m} \mathrm{~s}^{-1}$ for the filtered measurements.

\subsection{Second step: wavelet transform}

The continuous wavelet transform (CWT) unfolds a signal in both frequency and time and provides an efficient way to identify and localize abrupt changes or transients in nonstationary time series. The CWT is often used to identify and characterize coherent structures in turbulent flow (e.g. Dunyak et al., 1998; Krusche and de Oliveira, 2004; Fesquet et al., 2009) or wind power ramps (Gallego et al., 2013).

The CWT is formally defined as the inner product of a function $x(t)$ and a mother wavelet $\psi(t)$ that is shifted and dilated:

$W_{x}\left(\ell, t^{\prime}\right)=\frac{1}{\ell} \int_{-\infty}^{\infty} x(t) \psi\left(\frac{t-t^{\prime}}{\ell}\right) \mathrm{d} t$,

where the resulting wavelet coefficients $W_{x}$ are a function of the scale dilation $\ell$ and time shift $t^{\prime}$. Note that the factor $1 / \ell$ is a normalization resulting in wavelet coefficients in the $L^{1}$ norm, though this normalization is most commonly seen in the literature as $1 / \sqrt{\ell}$ giving a CWT in the $L^{2}$ norm (Farge, 1992). However, it is important when comparing wavelet coefficients (or the wavelet power spectrum) between different scales to do so in the $L^{1}$ norm, to prevent giving a bias toward the large scales (Liu et al., 2007).

The choice of analysing wavelet influences the results of the wavelet transform, since it reflects characteristics of the wavelet. We have therefore chosen a wavelet that includes features similar to those we look for in the signal, i.e. one dominating increase at the centre of the wavelet function. The analysing wavelet chosen here is the first derivative of 
a Gaussian (DOG1) wavelet ${ }^{3}$ :

$\psi(t)=C t \mathrm{e}^{-t^{2}}$,

where $C$ is a normalization constant, here equal to $2(2 / \pi)^{1 / 4}$. Note that we have switched the sign of the wavelet to get positive wavelet coefficients from the transform where there is an increase in the wind speed signal (Fig. 3b).

Figure 3 shows an example of a CWT of one of the detected high-variance events along with the mirrored DOG1 wavelet. Before performing the CWT the mean wind speed is subtracted from the wind speed signal and the signal is normalized with the standard deviation. The highest wavelet coefficients are shown with red, indicating a high correlation between the signal and the wavelet at that given time. The maximum wavelet coefficient of the CWT identifies the timing $\left(t^{\prime}\right)$ and the scale $(\ell)$ of the coherent structure.

\subsection{Third step: idealized ramp function}

The definition of the idealized ramp function is borrowed from Steyn et al. (1999), where they incorporate the error function into an idealized backscatter profile. The profile is fit to backscatter lidar measurements to identify the depth of the atmospheric boundary (mixed) layer, and the thickness of the entrainment zone. Wind speed measurements where the wind speed rapidly increases may often resemble these ideal backscatter profiles, and therefore we can use this method to characterize ramp-like fluctuations in the same manner. The idealized ramp wind speed function may be defined as

$u(t)=\frac{u_{\mathrm{b}}+u_{\mathrm{a}}}{2}+\frac{u_{\mathrm{a}}-u_{\mathrm{b}}}{2} \operatorname{erf}\left(\frac{t-t^{\prime}}{\tau}\right)$,

where $u_{\mathrm{b}}$ is the wind speed before the rise, $u_{\mathrm{a}}$ is the wind speed after the rise, and $\tau$ is a normalization constant. We define the rise time of the ramp from the interval where the wind speed rises from $u_{\mathrm{b}}+0.0125\left(u_{\mathrm{a}}-u_{\mathrm{b}}\right)$ to $u_{\mathrm{b}}+$ $0.9875\left(u_{\mathrm{a}}-u_{\mathrm{b}}\right)$. This value may be estimated by multiplying $\tau$ by 3.17 , which is found from ordinates of the error function. The parameters of the idealized ramp function are found by minimizing the least square differences between the measurements and the ramp function with an optimization curve fitting procedure ${ }^{4}$.

Figure 4 demonstrates the idealized ramp function that is fit to wind speed measurements from the different sites. The limited period that the ramp function is fit to is found by the CWT. The timing is given by $t^{\prime}$ and the period is 3 times the scale: $3 \cdot \ell$. The factor of 3 is used to ensure approximately equal periods of measurements before, during, and after the ramp-like increase for the curve fitting procedure.

\footnotetext{
${ }^{3}$ The wavelet transform is performed using Python package PyWavelets (Lee et al., 2006).

${ }^{4}$ For the optimization fitting procedure we employed the SciPy curve_fit function.
}

\subsection{Overview of the selection and characterization}

A brief summation of the detection: a subset of extremevariance events is found. The CWT is performed on each event and the timing and scale of the ramp-like wind speed increase are estimated. The scale $(3 \ell)$ is used to find a limited period of the wind speed signal to which the idealized ramp function is fit. The idealized ramp function parameters are used to estimate the amplitude of the ramp-like fluctuation, $\Delta u=u_{\mathrm{a}}-u_{\mathrm{b}}$, and the rise time, $\Delta t=3.17 \tau$.

As we want to compare the wind speed ramps with the ECD load case of the IEC standard, we investigate the direction change during the ramps. Here we use the directional data at $\approx 100 \mathrm{~m}$ from each site and calculate the moving $30 \mathrm{~s}$ average during the time of the ramp function at $\approx 100 \mathrm{~m}$.

The direction change during the ramp-like wind speed increase is determined as the difference between the maximum value and the minimum value of the moving average.

An example of a ramp event at Østerild is shown in Fig. 5 along with the corresponding directional data. The orange line in the lower panel shows the $30 \mathrm{~s}$ moving average during the ramp function period at $103 \mathrm{~m}$. The moving average is applied to the directional measurements in order to filter out the small-scale fluctuations that we do not want to influence the estimated direction change.

The amplitudes and rise times are characterized for each measurement height. Afterwards the values are averaged over the three different heights to give the characteristic rise time and amplitude for each event.

\section{IEC extreme coherent gust with direction change}

The extreme coherent gust with direction change (ECD) is modelled with an amplitude of $V_{\mathrm{cg}}=15 \mathrm{~m} \mathrm{~s}^{-1}$ and a direction change

$\theta_{\mathrm{cg}}= \begin{cases}180^{\circ}, & \text { if } V_{\mathrm{hub} \leq 4 \mathrm{~m} \mathrm{~s}^{-1} .} \\ 720^{\circ}\left[\mathrm{m} \mathrm{s}^{-1}\right] / V_{\text {hub }}, & \text { if } 4 \mathrm{~m} \mathrm{~s}^{-1}<V_{\text {hub }}<V_{\text {ref }},\end{cases}$

where $V_{\text {hub }}$ is the $10 \mathrm{~min}$ mean wind speed at hub height and $V_{\text {ref }}$ is the $10 \mathrm{~min}$ mean reference wind speed. Both the direction change and wind speed change are modelled as functions of time,

$\theta_{\mathrm{cg}}(t)= \begin{cases}0^{\circ}, & \text { if } t<0 \\ \pm 0.5 \theta_{\mathrm{cg}}(1-\cos (\pi t / T)), & \text { if } 0 \leq t \leq T \\ \pm \theta_{\mathrm{cg}}, & \text { if } t>T,\end{cases}$
$V(z, t)= \begin{cases}V(z), & \text { if } t<0 \\ V(z)+0.5 V_{\mathrm{cg}}(1-\cos (\pi t / T)), & \text { if } 0 \leq t \leq T \\ V(z)+V_{\mathrm{cg}}, & \text { if } t>T,\end{cases}$

where $T=10 \mathrm{~s}$ is the rise time. The direction change and wind speed increase are assumed to occur simultaneously. 

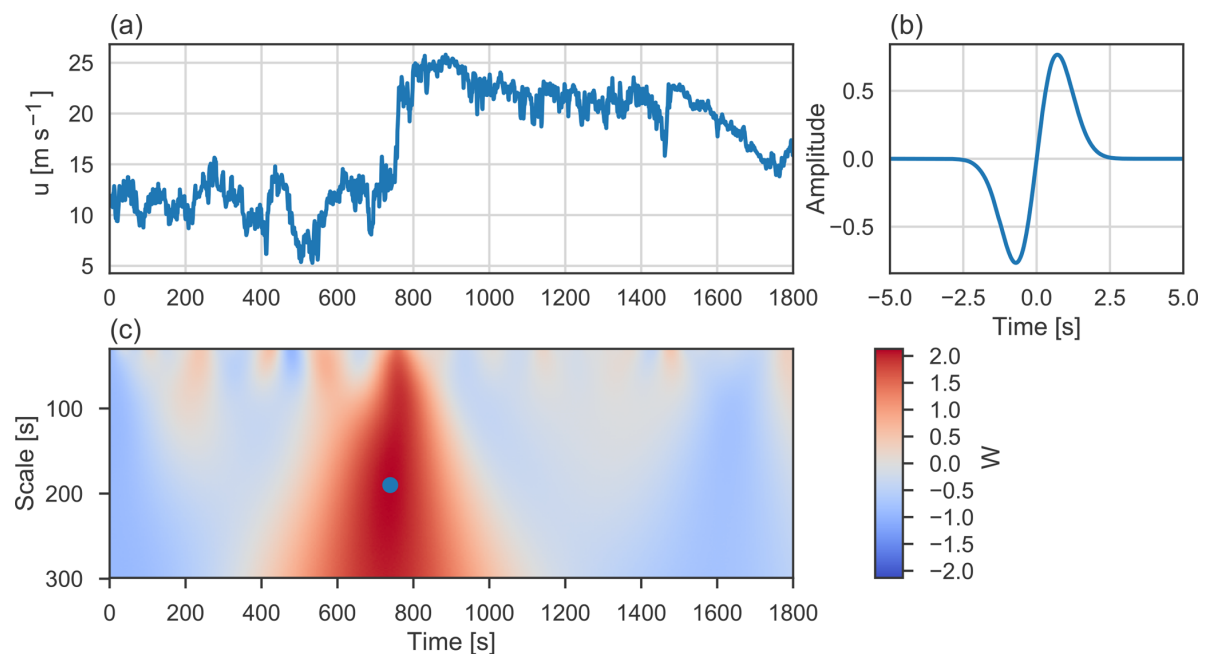

Figure 3. The continuous wavelet transform of a ramp-like coherent structure. (a): $30 \mathrm{~min}$ wind speed signal at $100 \mathrm{~m}$, Høvsøre. (b): the flipped DOG1 wavelet used for the wavelet transform. (c): the wavelet coefficients of the normalized wind speed signal. The maximum coefficient is shown with a blue dot at $\ell=190 \mathrm{~s}$ and $t^{\prime}=739 \mathrm{~s}$.
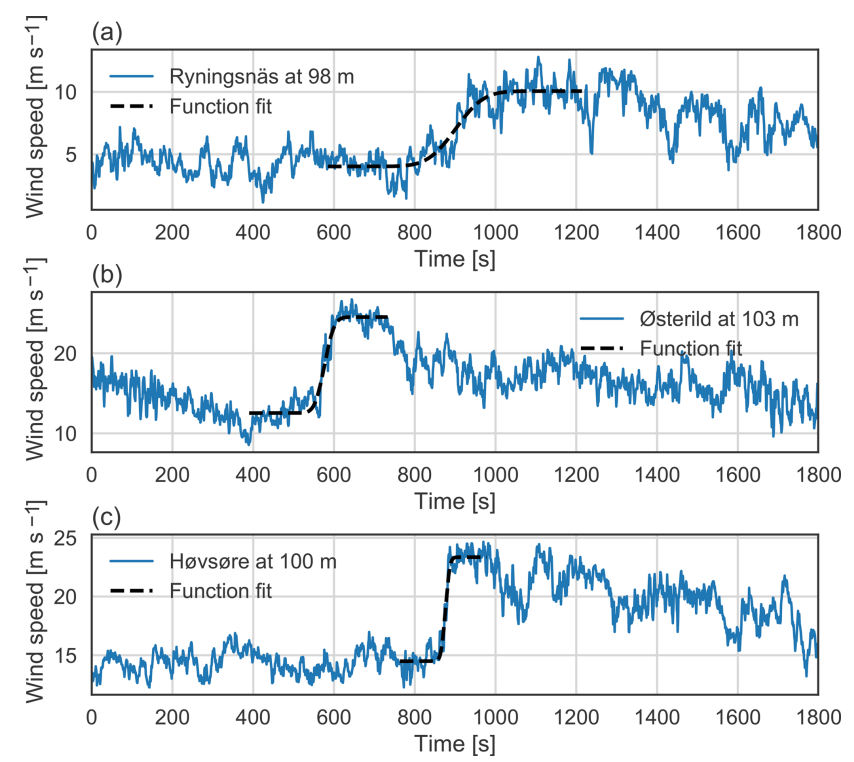

Figure 4. Three examples of the idealized ramp function fit to the wind speed measurements. Measurements from (a) Ryningsnäs, (b) Østerild, and (c) Høvsøre. The blue lines show the measurements and the dashed black lines show the idealized ramp function fit to a subset of the measurement.

Figure 6 shows the ECD for $V_{\text {hub }}=V_{\mathrm{r}}=11.4 \mathrm{~m} \mathrm{~s}^{-1}$, which is the rated wind speed for e.g. the NREL $5 \mathrm{MW}$ and DTU $10 \mathrm{MW}$ reference wind turbines (Jonkman et al., 2009; Bak et al., 2013). According to the IEC standard, the design load case with the ECD should be simulated at $V_{\mathrm{r}} \pm 2 \mathrm{~m} \mathrm{~s}^{-1}$.
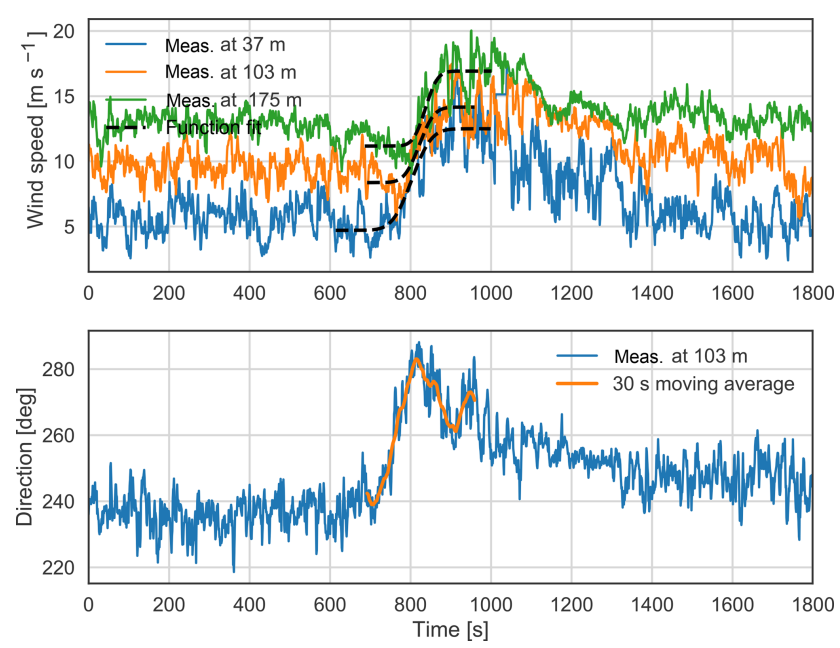

Figure 5. The idealized ramp function fit to Østerild measurements at three different heights and the corresponding direction change.

\section{Distributions and comparison with the ECD}

In this section we look at the amplitudes, rise times, and direction change in the detected events and how these variables are distributed. Selecting the $0.1 \%$ highest ratios of $\sigma_{\text {raw }} /\left(\sigma_{\text {filt }}+1\right)$ results in 453 events from Høvsøre, 154 from Østerild, and 58 from Ryningsnäs. A number of these events are discarded before performing the characterization, for one of three reasons: because the measurements are partly missing; because the measurements are from a wind direction sector where the nearby wind turbines are upstream of the masts (in the wake of the wind turbines); or because the high observed variance is due to a wind speed decrease (negative ramps). The negative ramps are identified when the dominat- 

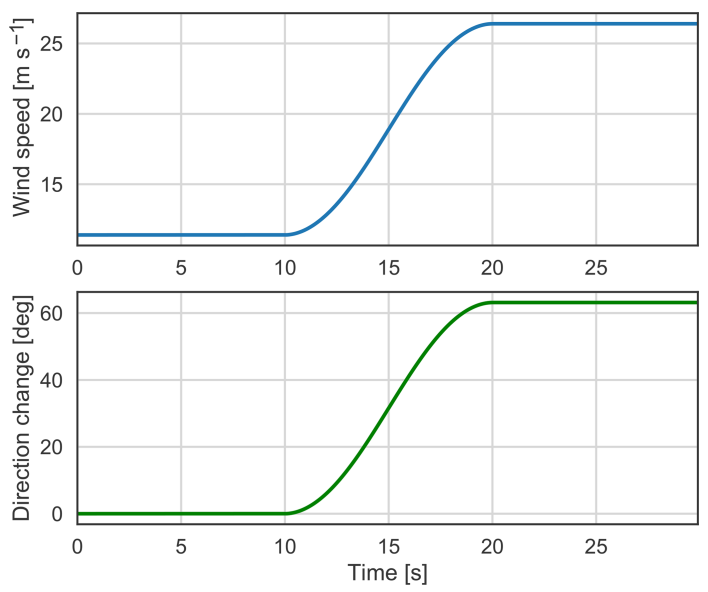

Figure 6. The extreme coherent gust with direction change from the IEC wind turbine safety standard.

ing wavelet coefficients are negative. The discarding narrows the number of analysed events down to 216 from Høvsøre, 72 from Østerild, and 32 from Ryningsnäs.

The estimated $\Delta u, \Delta \theta$, and $\Delta t$ variables for each detected event and their distribution may be seen in Fig. 7. The variables are shown with different colours for each measurement site, black for Høvsøre, blue for Østerild, and green for Ryningsnäs. It may be seen that the highest values of each parameter are found from the Høvsøre data set, which has the longest measurement period.

The sample means and the corresponding standard deviations of $\Delta u, \Delta \theta$, and $\Delta t$ for each site may be found in Table 1 . Though the variables are not normally distributed, we choose to show the standard deviation to indicate the spread of the variables. The average $\Delta u$ and $\sigma_{\Delta u}$ are of similar magnitude for all sites.

We see that the average $(\Delta \theta)$ and standard deviation of direction change $\left(\sigma_{\Delta \theta}\right)$ found in Ryningsnäs are nearly twice the value found at Østerild and significantly higher than at Høvsøre.

The average $\Delta t$ and $\sigma_{\Delta t}$ are lowest for the Østerild site, and there are no events detected with a rise time above $485 \mathrm{~s}$, while the maximum estimated rise times in Ryningsnäs and Høvsøre are 887 and 952 s respectively.

Figure 8 shows the detected events as functions of mean wind speed compared with the ECD model. The mean wind speed is the average of $u_{\mathrm{b}}$ and $u_{\mathrm{a}}$, which may be taken as the representative wind speed of the events. A similar figure has been made showing the events as functions of $u_{\mathrm{b}}$ and may be found in Appendix A. The dashed lines show the IEC prescription of $\Delta u, \Delta \theta$, and $\Delta t$ for the ECD. The solid lines show the variables averaged over wind speed bins where the bin width is $2 \mathrm{~m} \mathrm{~s}^{-1}$. The shaded colours mark the area between the 10th percentile and the 90th percentile of the variables in each bin. When comparing the estimated $\Delta u$ to the IEC prescribed amplitude, it is seen that there is not a single
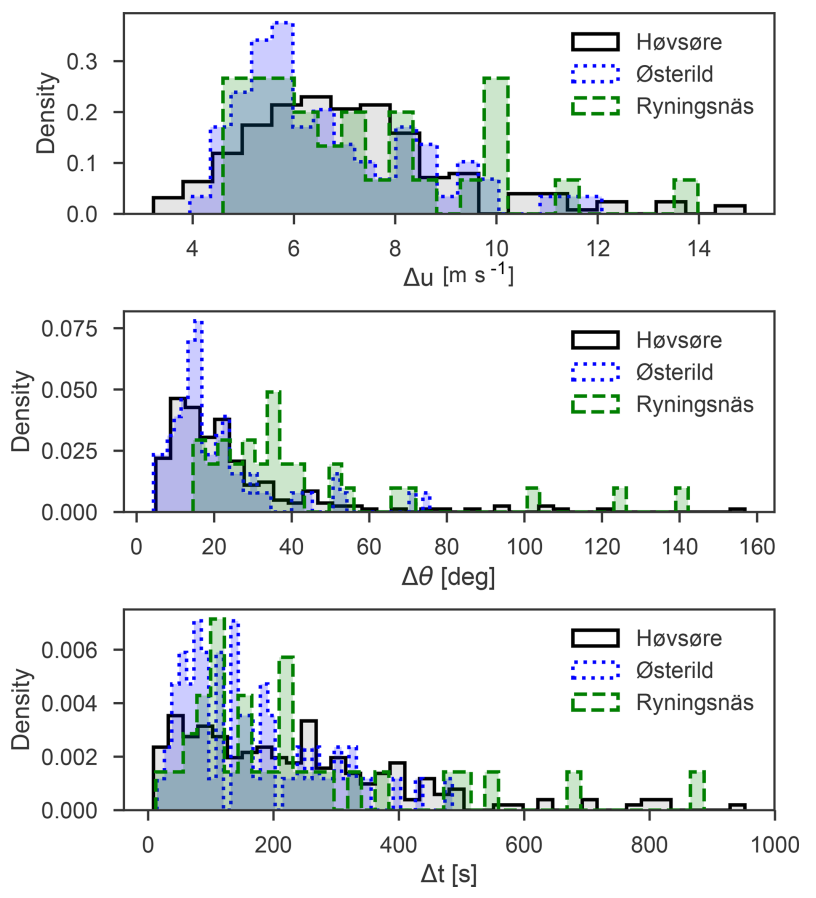

Figure 7. The distributions of detected amplitudes $(\Delta u)$, direction changes $(\Delta \theta)$, and rise times $(\Delta t)$ of all the detected events at the three different sites: Høvsøre (grey), Østerild (blue), and Ryningsnäs (green).

event that exceeds $15 \mathrm{~m} \mathrm{~s}^{-1}$. There is a number of events that exceed the prescribed direction change in the ECD, one at Ryningsnäs, one at Østerild, and seven at Høvsøre. These extreme direction events are indicated with a black circle in the different plots. The amplitude of the extreme direction events in Høvsøre ranges from $\Delta u=[5.5,14,9] \mathrm{m} \mathrm{s}^{-1}$ and the rise times range from $\Delta t=[174,807] \mathrm{s}$. The extreme direction event at Østerild has a direction change in $\Delta \theta=70^{\circ}$, an amplitude of $\Delta u=8.4 \mathrm{~m} \mathrm{~s}^{-1}$, and a rise time of $\Delta t=58 \mathrm{~s}$. At Ryningsnäs the extreme direction event has $\Delta \theta=101^{\circ}$, $\Delta u=8.2 \mathrm{~m} \mathrm{~s}^{-1}$, and $\Delta t=256 \mathrm{~s}$.

\section{Discussion}

\subsection{Discussion on the detection and characterization method}

The CWT is ideal for finding abrupt changes in a wind speed signal and can provide useful information on different scales of the flow. Here we use the wavelet transform to provide an objective estimate of the timescale of the ramp-like wind speed increase as well as the precise timing in the signal. To obtain characteristics of the amplitude and rise time of these fluctuations, we need an additional step, which is inspired by mixed-layer height detection performed by fitting an idealized profile to backscatter measurements. 
Table 1. The number of analysed events and average estimated variables from each site.

\begin{tabular}{l|r|r|r}
\hline & Høvsøre & Østerild & Ryningsnäs \\
\hline No. of analysed events & 216 & 72 & 32 \\
$\langle\Delta u\rangle \pm \sigma_{\Delta u}$ & $7.1 \pm 2.1 \mathrm{~m} \mathrm{~s}^{-1}$ & $6.7 \pm 1.8 \mathrm{~m} \mathrm{~s}^{-1}$ & $7.3 \pm 2.2 \mathrm{~m} \mathrm{~s}^{-1}$ \\
$\langle\Delta \theta\rangle \pm \sigma_{\Delta \theta}$ & $25 \pm 21^{\circ}$ & $21 \pm 14^{\circ}$ & $42 \pm 30^{\circ}$ \\
$\langle\Delta t\rangle \pm \sigma_{\Delta t}$ & $232 \pm 177 \mathrm{~s}$ & $160 \pm 105 \mathrm{~s}$ & $233 \pm 195 \mathrm{~s}$ \\
\hline
\end{tabular}
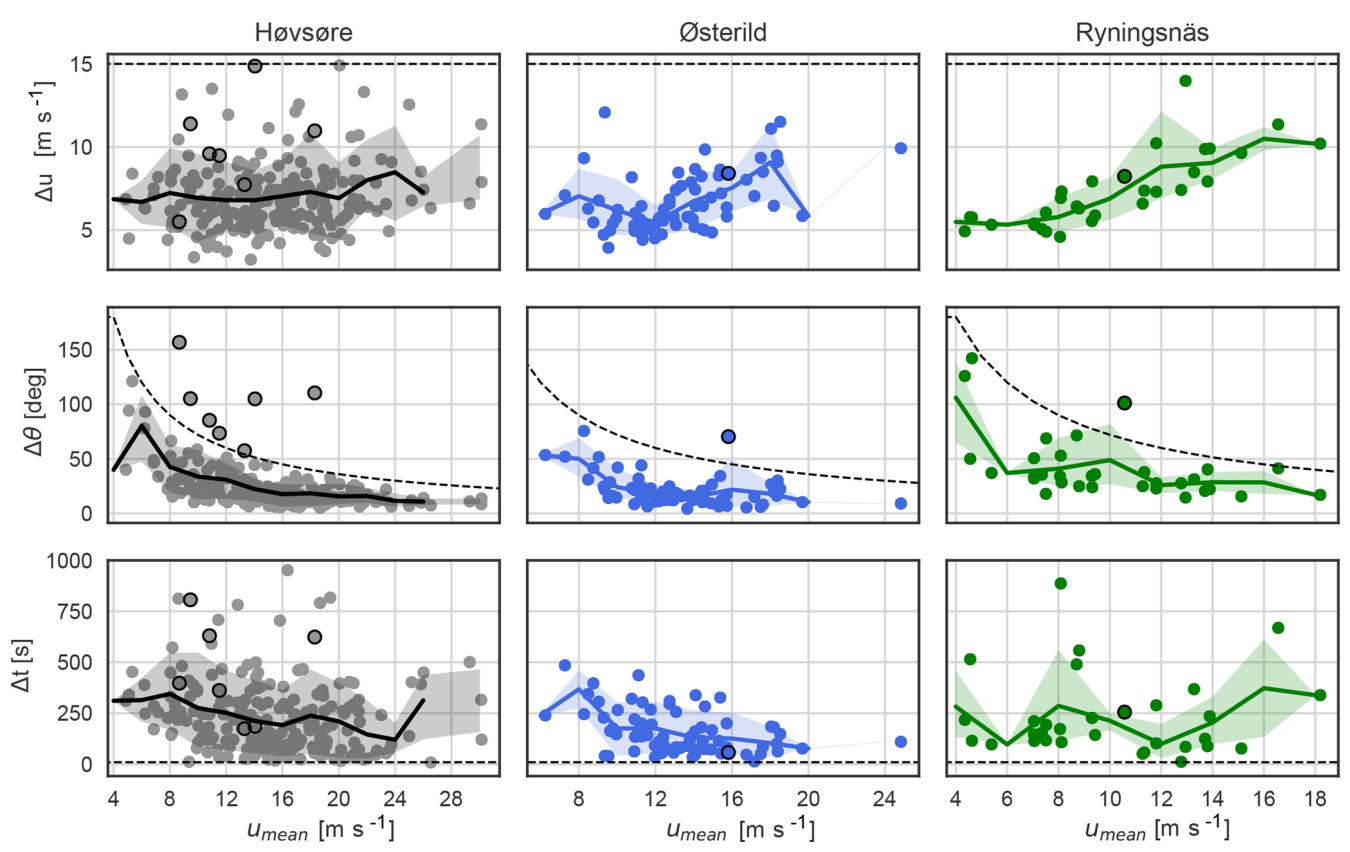

Figure 8. The detected amplitudes $(\Delta u)$, direction changes $(\Delta \theta)$, and rise times $(\Delta t)$ as functions of the mean wind speed at the different sites: Høvsøre (grey), Østerild (blue), and Ryningsnäs (green). The plots share the primary axis (abscissa) per column, and they share the secondary axis (ordinate) per row. The shaded area indicates events between the 10th percentile and 90th percentile for each wind speed bin, with bin width $2 \mathrm{~m} \mathrm{~s}^{-1}$. The black dashed lines show the ECD values.

The main difference between backscatter profiles and wind speed time series is that the wind speed continuously fluctuates through time and the period of the coherent structure we investigate is finite. This difference is why the wavelet analysis is important prior to the fitting of the idealized function, where the limited period of the ramp and the timing is identified. We found the optimal period for the fitting to be 3 times the scale dilation $(3 \cdot \ell)$ of the DOG1 wavelet as defined in Sect. 3.2. If this limited period is not long enough, the numerical curve fitting procedure might not always find an optimal solution to the fitting parameters. Having enough measurement points for a curve fitting procedure is what makes the method robust, as pointed out by Steyn et al. (1999). However, for the purpose of characterizing wind speed fluctuations, it is important that the chosen fitting period is not longer than necessary. We see e.g. for the wind speed fluctuations in Fig. 4 that the wind speed decreases shortly after the ramp; if this decrease is included in the curve fitting, the amplitude of the estimated ramp would be underestimated. The choice of $3 \cdot \ell$ provides the shortest period that makes the combined method robust in the sense that it always results in a successful fit with an estimate of the desired parameters.

The first step in the selection, choosing high-variance events, is used for two purposes: first, to ensure that the selected ramp-like fluctuations are associated with scales that are large enough to cover any rotor of a multi-megawatt wind turbine. We have seen in a previous study that these fluctuations occur approximately simultaneously at two different measurement masts in Høvsøre that are separated by $400 \mathrm{~m}$ transverse to the mean wind direction (Hannesdóttir et al., 2019).

Second, by choosing a subset of events, we avoid performing a CWT on the whole data set of high-frequency measurements, which is computationally demanding on a 10 -year data set like the one from Høvsøre. If a CWT is performed on the whole data set, an extra step would be needed in the analysis to decide whether a structure is coherent or not, e.g. to apply a threshold on the scale-averaged wavelet coefficients or wavelet spectrum (e.g. Farge, 1992; Dunyak et al., 1998). 


\subsection{Discussion of observed distributions}

The main difference between the observed fluctuations analysed in the current study and the classic ECD (investigated in Stork et al., 1998; Hansen and Larsen, 2007) is that in the current study we only characterize large-scale coherent structures, whereas the ECD is based on measurements where all extreme peaks of small-scale turbulence are considered. By extracting ramp events from the measurements, we exclude the small-scale fluctuations from the characterization of the amplitude and rise time (see Figs. 4 and 5). Even though Hansen and Larsen (2007) only consider 10 s rise times from a data set with a 2-year period, they find gust amplitudes in a similar range to the current study. This is because smallscale turbulent fluctuations can have very high peak values. However, such fluctuations are not coherent across rotor diameters of multi-megawatt wind turbines and have much less impact than coherent ramps on loads for such turbines.

We observe that the average amplitudes of ramp-like fluctuations $(\langle\Delta u\rangle)$ are of similar magnitude at all the sites considered, although the reference turbulence intensity is different at the sites $(0.065$ at Høvsøre, 0.13 at Østerild, and 0.18 at Ryningsnäs). This is likely because these large coherent structures are caused by mesoscale phenomena, observed at heights above the surface layer. As shown in Fig. 8, $\Delta u$ has negligible wind speed dependence at Høvsøre and Østerild, but at Ryningsnäs the ramp amplitudes increase with mean wind speed. The direction change generally decreases with wind speed at all the sites, but significantly larger mean change $\langle\Delta \theta\rangle$ is observed over ramps at Ryningsnäs. These observations are consistent with the (low-order, dominant) physics of the sites: Ryningsnäs has appreciably taller trees than Østerild, with the Ryningsnäs observations taken at roughly 2-5 times tree height; the measurements used from Østerild correspond to 5-15 times the respective tree heights there. Thus the measurements at Ryningsnäs are more affected by the tree-induced turbulent stresses (e.g. Raupach et al., 1996; Sogachev and Kelly, 2016). In particular, a windspeed (Reynolds-number) dependence arises in the turbulent degradation of the coherent structures, and there is more turning of the wind due to the relatively larger drag. It should also be noted that the mean wind speed is generally lower at Ryningsnäs and, with the observed wind speed dependence of the direction change, the average direction change is higher.

\section{Are the ramps comparable to the ECD?}

The rise time of the ramp-like fluctuations is generally much higher than that of the ECD. But the range is large: e.g. at Høvsøre the rise time ranges over 2 orders of magnitude (from 9 to $952 \mathrm{~s}$ ). The rise time of the extreme direction events is of the order of a minute or more. Although these extreme direction events generally have a longer rise time than the defined ECD, they could readily be considered for load simulation purposes. The reason is that a wind turbine reacts much more slowly to changes in wind direction than to changes in wind speed. The yaw speed of a wind turbine is typically less than $0.5^{\circ} \mathrm{s}^{-1}$, which means that yawing $90^{\circ}$ takes more than $3 \mathrm{~min}$. Hence, during one of the extreme direction events, a wind turbine is continuously exposed to yaw misalignment, while the wind speed keeps increasing.

We observe ramp events that either have an amplitude, or rise time, or direction change of the same order of magnitude as the ECD. However, no single event is comparable to the ECD on all three variables at once. In order to predict an extreme event considering all three variables simultaneously, one would need a multivariate distribution model including the parameter distributions. That way it would be possible to model the probability of different positions in the threeparameter space and extrapolate to desired return periods.

\section{Conclusions}

The combination of the wavelet transform and the fitting of an idealized ramp function is a new and efficient way to characterize extreme wind speed ramps. The characterization provides variables that are relevant for wind energy, particularly for wind turbine load simulations, probabilistic design, and wind turbine safety standards.

We use measurements from three measurement sites in different terrain to calculate statistics of the amplitudes, direction change, and rise time of extreme ramp-like fluctuations, and also compare the estimated variables with the ECD load case of the IEC standard. Here we find the following.

- The amplitudes of these coherent structures do not exceed the amplitude of the ECD (using 10, 3, and 1 year of data respectively).

- The amplitudes show no clear wind speed dependence at Høvsøre and Østerild, but at Ryningsnäs the amplitudes increase with increasing wind speed.

- The direction change may exceed that of the ECD, but for those events the rise time is a minute or more.

Future related work includes further analysis of ramp events, in particular, using a multivariate distribution model based on the marginal distributions of the ramp variables to estimate ramp events with a 50-year return period.

Code and data availability. The high-frequency measurements used in this study are stored in an SQL database at DTU that is not publicly accessible. However, we provide a subset of the data with six ramp events of 30 min duration. A Python script may be applied to these data to perform the ramp characterization described in the paper. This Python script and data are available at https: //gitlab.windenergy.dtu.dk/astah/ramp-characterization (last access: 29 May 2019) (Hannesdóttir, 2019). Contact Ásta Hannesdóttir for further questions regarding the code. 


\section{Appendix A}

The figure in this Appendix is equivalent to Fig. 8, but shows the estimated variables as a function of the speed $u_{\mathrm{b}}$ preceding the ramp.

Note that the IEC direction change prescription looks more reasonable when using $u_{\mathrm{b}}$. This is because $u_{\mathrm{b}}$ is lower than the average of $u_{\mathrm{b}}$ and $u_{\mathrm{a}}$ and the events get shifted to the left by using $u_{\mathrm{b}}$ when compared with Fig. 8. This difference is greatest for the large-amplitude events.
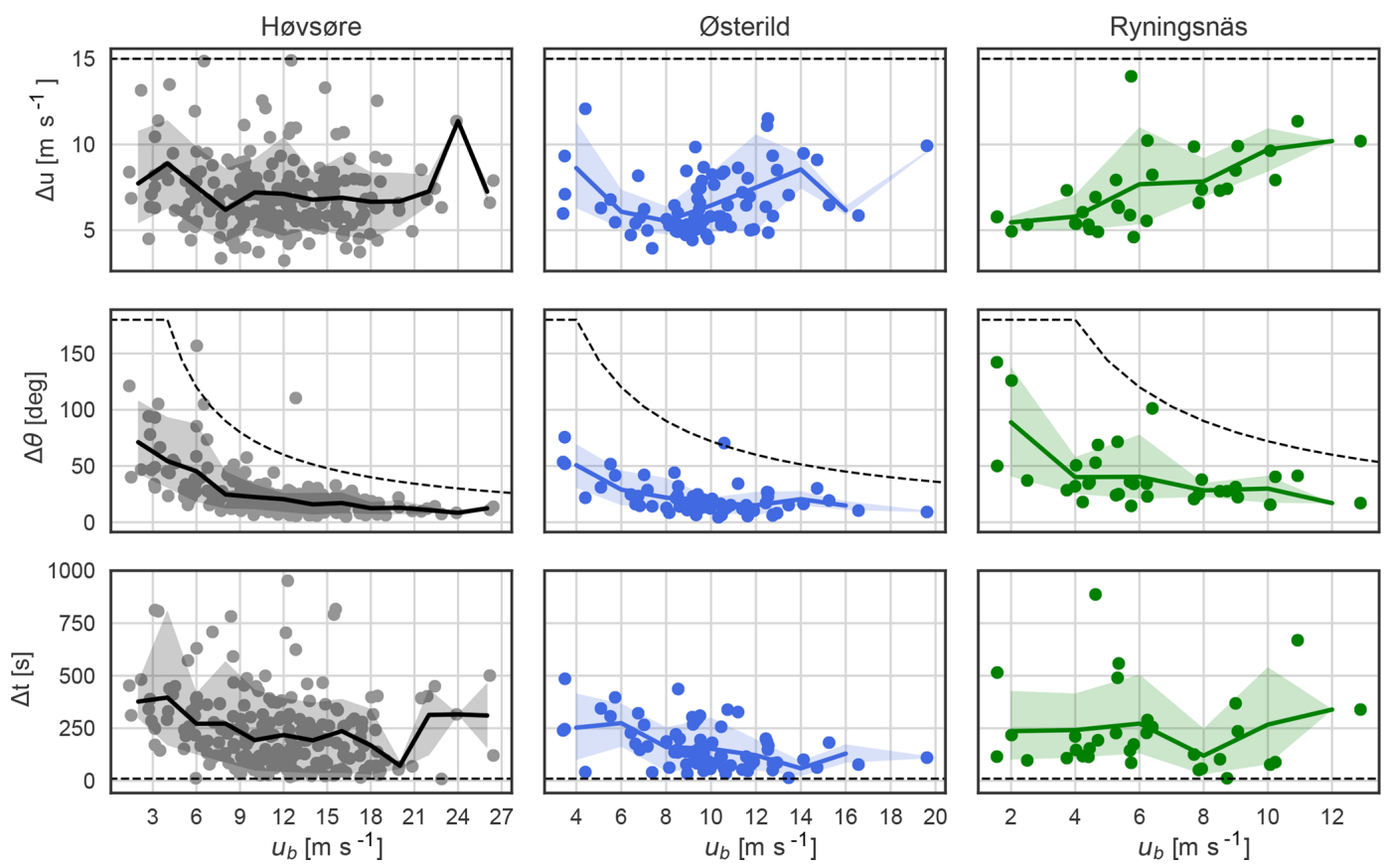

Figure A1. The detected amplitudes $(\Delta u)$, direction changes $(\Delta \theta)$, and rise times $(\Delta t)$ as a function of speed preceding the ramp $\left(u_{\mathrm{b}}\right)$ at the different sites: Høvsøre (grey), Østerild (blue), and Ryningsnäs (green). The plots share the primary axis (abcissa) per column and they share the secondary axis (ordinate) per row. The black dashed lines show the ECD values. 
Appendix B: List of abbreviations and symbols

CWT Continuous wavelet transform

ECD Extreme coherent gust with direction change

IEC International Electrotechnical Commission (standard 61400-1)

$f_{c} \quad$ High-pass filter frequency

$I_{\text {ref }} \quad$ IEC reference turbulence intensity

$L \quad$ Length-scale "cutoff" between meso- and micro-scale motions

$\ell \quad$ Time-dilation scale in wavelet transform

$t^{\prime} \quad$ Time shift

$U \quad 10$ min mean wind speed

$u_{\mathrm{a}} \quad$ Wind speed after the ramp rise

$u_{\mathrm{b}} \quad$ Wind speed before the ramp rise

$V_{\text {ave }} \quad$ IEC annual average 10 min wind speed

$V_{\text {cg }} \quad$ IEC ECD amplitude

$V_{\text {hub }} \quad$ IEC average 10 min wind speed at hub height

$V_{\mathrm{r}} \quad$ IEC rated wind speed

$V_{\text {ref }} \quad$ IEC $10 \mathrm{~min}$ reference wind speed

$W_{x} \quad$ Wavelet coefficient

$\Delta t \quad$ Rise time

$\Delta u \quad$ Amplitude

$\Delta \theta \quad$ Direction change

$\psi(t) \quad$ Mother wavelet

$\sigma_{\text {filt }} \quad$ Standard deviation of high-pass filtered 10 min measurements

$\sigma_{\text {raw }} \quad$ Standard deviation of raw 10 min measurements

$\tau \quad$ Time normalization constant

$\theta_{\mathrm{cg}} \quad$ IEC ECD direction change 
Author contributions. ÁH provided the detection method, performed the data analysis, and made the figures. MK provided guidance and comments. ÁH prepared the manuscript with contributions from MK.

Competing interests. The authors declare that they have no conflict of interest.

Acknowledgements. This work was part of Ásta Hannesdóttir's $\mathrm{PhD}$ at DTU Wind Energy under the supervision of Mark Kelly.

Review statement. This paper was edited by Ola Carlson and reviewed by Anders Wickström and Matti Koivisto.

\section{References}

Arnqvist, J., Segalini, A., Dellwik, E., and Bergström, H.: Wind Statistics from a Forested Landscape, Bound.-Lay. Meteorol., 156, 53-71, https://doi.org/10.1007/s10546-015-0016-x, 2015.

Bak, C., Zahle, F., Bitsche, R., Kim, T., Yde, A., Henriksen, L. C., Natarajan, A., and Hansen, M.: Description of the DTU 10 MW Reference Wind Turbine, Tech. rep., DTU Wind Energy, Roskilde, Denmark, 2013.

Barthlott, C., Drobinski, P., Fesquet, C., Dubos, T., and Pietras, C.: Long-term study of coherent structures in the atmospheric surface layer, Bound.-Lay. Meteorol., 125, 1-24, https://doi.org/10.1007/s10546-007-9190-9, 2007.

Belušić, D. and Mahrt, L.: Is geometry more universal than physics in atmospheric boundary layer flow?, J. Geophys. Res.-Atmos., 117, 1-10, https://doi.org/10.1029/2011JD016987, 2012.

Bierbooms, W.: Investigation of spatial gusts with extreme rise time on the extreme loads of pitch-regulated wind turbines, Wind Energy, 8, 17-34, https://doi.org/10.1002/we.139, 2005.

Bos, R., Bierbooms, W., and van Bussel, G.: Towards spatially constrained gust models, J. Phys. Conf. Ser., 524, 012107, https://doi.org/10.1088/1742-6596/524/1/012107, 2014.

Drobinski, P., Brown, R. A., Flamant, P. H., and Pelon, J.: Evidence of organized large eddies by ground-based Doppler lidar, sonic anemometer and sodar, Bound.-Lay. Meteorol., 88, 343361, https://doi.org/10.1023/A:1001167212584, 1998.

Dunyak, J., Gilliam, X., Peterson, R., and Smith, D.: Coherent gust detection by wavelet transform, J. Wind Eng. Ind. Aerod., 77-78, 467-478, https://doi.org/10.1016/S0167-6105(98)001652, 1998.

Farge, M.: Wavelet Transforms And Their Applications To Turbulence, Annu. Rev. Fluid Mech., 24, 395-457, https://doi.org/10.1146/annurev.fluid.24.1.395, 1992.

Fesquet, C., Drobinski, P., Barthlott, C., and Dubos, T.: Impact of terrain heterogeneity on near-surface turbulence structure, Atmos. Res., 94, 254-269, https://doi.org/10.1016/j.atmosres.2009.06.003, 2009.

Finnigan, J.: Turbulence in Plant Canopies, Annu. Rev. Fluid Mech., 32, 519-571, https://doi.org/10.1146/annurev.fluid.32.1.519, 2000 .
Foster, R. C., Vianey, F., Drobinski, P., and Carlotti, P.: Near-surface coherent structures and the vertical momentum flux in a large-eddy simulation of the neutrallystratified boundary layer, Bound.-Lay. Meteorol., 120, 229-255, https://doi.org/10.1007/s10546-006-9054-8, 2006.

Gallego, C., Costa, A., Cuerva, Á., Landberg, L., Greaves, B., and Collins, J.: A wavelet-based approach for large wind power ramp characterisation, Wind Energy, 16, 257-278, https://doi.org/10.1002/we.550, 2013.

Hannesdóttir, Á.: Characterization of extreme wind speed ramps, available at: https://gitlab.windenergy.dtu.dk/astah/ ramp-characterization, last access: 29 May 2019.

Hannesdóttir, Á., Kelly, M., and Dimitrov, N.: Extreme wind fluctuations: joint statistics, extreme turbulence, and impact on wind turbine loads, Wind Energ. Sci., 4, 325-342, https://doi.org/10.5194/wes-4-325-2019, 2019.

Hansen, B. O., Courtney, M., Mortensen, N. G., Hansen, A. B. O., Courtney, M., and Mortensen, N. G.: Wind Resource Assessment — Østerild National Test Centre for Large Wind Turbines Wind Energy E Report 2014, Tech. Rep. August, DTU Wind Energy, Roskilde, Denmark, 2014.

Hansen, K. S. and Larsen, G. C.: Full scale experimental analysis of extreme coherent gust with wind direction changes (EOD), J. Phys. Conf. Ser., 75, 012055, https://doi.org/10.1088/17426596/75/1/012055, 2007

IEC: IEC 61400-1 Ed3: Wind turbines - Part 1: Design requirements, standard, International Electrotechnical Commission, Geneva, Switzerland, 2005.

Jonkman, J., Butterfield, S., Musial, W., and Scott, G.: Definition of a 5-MW Reference Wind Turbine for Offshore System Development, Tech. Rep. February, National Renewable Energy Laboratory, Golden, CO, USA, https://doi.org/10.2172/947422, 2009.

Krusche, N. and de Oliveira, A.: Characterization of coherent structures in the atmospheric surface layer, Bound.-Lay. Meteorol., 110, 191-211, 2004.

Lee, G., Gommers, R., Wasilewski, F., Wohlfahrt, K., O’Leary, A., Nahrstaedt, H., and Contributors: PyWavelets - Wavelet Transforms in Python, available at: https://github.com/PyWavelets/ pywt (last access: 15 October 2018), 2006.

Liu, Y., Liang, X. S., and Weisberg, R. H.: Rectification of the bias in the wavelet power spectrum, J. Atmos. Ocean. Tech., 24, 2093-2102, https://doi.org/10.1175/2007JTECHO511.1, 2007.

Mahrt, L.: Eddy Asymmetry in the Sheared Heated Boundary Layer, J. Atmos. Sci., 48, 472-492, https://doi.org/10.1175/15200469(1991)048<0472:EAITSH>2.0.CO;2, 1991.

Mahrt, L.: Common microfronts and other solitary events in the nocturnal boundary layer, Q. J. Roy. Meteor. Soc., 136, 17121722, https://doi.org/10.1002/qj.694, 2010.

Peña, A., Floors, R., Sathe, A., Gryning, S. E., Wagner, R., Courtney, M. S., Larsén, X. G., Hahmann, A. N., and Hasager, C. B.: Ten Years of Boundary-Layer and Wind-Power Meteorology at Høvsøre, Denmark, Bound.-Lay. Meteorol., 158, 1-26, https://doi.org/10.1007/s10546-015-0079-8, 2016.

Raupach, M., Finnigan, J., and Brunet, Y.: Coherent eddies and turbulence in vegetation canopies: the mixing-layer analogy, Bound.-Lay. Meterorol., 78, 351-382, 1996. 
Sevlian, R. and Rajagopal, R.: Detection and statistics of wind power ramps, IEEE T. Power Syst., 28, 3610-3620, https://doi.org/10.1109/TPWRS.2013.2266378, 2013.

Sogachev, A. and Kelly, M.: On Displacement Height, from Classical to Practical Formulation: Stress, Turbulent Transport and Vorticity Considerations, Bound.-Lay. Meteorol., 158, 361-381, https://doi.org/10.1007/s10546-015-0093-x, 2016.

Steyn, D. G., Baldi, M., and Hoff, R. M.: The detection of mixed layer depth and entrainment zone thickness from lidar backscatter profiles, . Atmos. Ocean. Tech., 16, 953-959, https://doi.org/10.1175/15200426(1999)016<0953:TDOMLD>2.0.CO;2, 1999.

Stork, C. H., Butterfield, C. P., Holley, W., Madsen, P. H., and Jensen, P. H.: Wind conditions for wind turbine design proposals for revision of the IEC 1400-1 standard, J. Wind Eng. Ind. Aerod., 74-76, 443-454, https://doi.org/10.1016/S01676105(98)00040-3, 1998.
Vincent, C. L., Hahmann, A. N., and Kelly, M.: Idealized Mesoscale Model Simulations of Open Cellular Convection Over the Sea, Bound.-Lay. Meteorol., 142, 103-121, https://doi.org/10.1007/s10546-011-9664-7, 2012.

Young, G. S., Kristovich, D. A. R., Hjelmfelt, M. R., and Foster, R. C.: Rolls, Streets, Waves, and More: A Review of Quasi-Two-Dimensional Structures in the Atmospheric Boundary Layer, B. Am. Meteorol. Soc., 83, 997-1001, https://doi.org/10.1175/15200477(2002)083<0997:RSWAMA>2.3.CO;2, 2002. 